\title{
O PENSAMENTO DE ENRIQUE DUSSEL: UM OLHAR CRÍTICO PELO \\ PRISMA ARENDTIANO
}

\section{Evandro Fonseca Costa ${ }^{1}$}

\section{Dr. Junot Cornélio Matos²}

\begin{abstract}
RESUMO
O texto O pensamento de Enrique Dussel: um olhar crítico pelo prisma arendtiano trata-se de um exercício de (re)leitura da obra do pensador argentino que, nos anos 70/80, cumpriu o papel de motivar e mobilizar parte da intelectualidade latino-americana. Adotando o esquema "com Dussel, para além de Dussel", o presente trabalho estrutura-se em duas partes: na primeira, destaca aspectos marcantes do pensamento dusseliano, reveladores da perspectiva assumida por sua filosofia e do compromisso ético que seu pensamento inspira. São eles: a afirmação de uma Identidade latino-americana; uma antropologia latino-americana: o rosto ameríndio do homem; o princípio ético da alteridade: o pôr-se frente ao outro como pobre/excluído; na segunda, breves considerações críticas serão feitas ao pensamento dusseliano. São elas: os silêncios de Dussel: ingenuidade ou furtiva estratégia ideológica?, onde se observa que a utilização, mui parcial, de conceitos de Gramsci e Foucault, compromente a problematização de decorrências práticas implicadas em seu projeto; Dussel e a senda estreita do marxismo, onde se analisa os comprometimentos daí advindos para seu pensamento; o flerte com uma razão estratégica: a instrumentalização do agir e do pensar, onde se constata que Dussel tornou-se refém das mazelas e dos descaminhos da racionalidade moderna que ele pretendeu superar.
\end{abstract}

Palavras-chave: Dussel; Filosofia latino-americana; Crítica arendtiana.

Detive-me na análise e no exame de todos os pormenores da causalidade, como exemplificadores na passagem da vida à morte, e da morte à vida, até que, no meio dessa escuridão, subitamente uma luz jorrou sobre mim - uma luz tão brilhante e maravilhosa, e ainda assim tão simples, que, embora tenha ficado tonto com a imensidade das perspectivas que ela me oferecia, surpreendi-me com o fato de que, entre tantos homens geniais que haviam conduzido suas pesquisas rumo à mesma ciência, somente eu teria o privilégio de descobrir um segredo tão maravilhoso

Victor Frankenstein, personagem do clássico de Mary Shelley

1 Doutorando em Filosofia pela UFPE/UFPB/UFRN. E-mail: vandro.filosofia@gmail.com

2 Orientador. Doutor em Filosofia. Professor da UFPE 
Lendo essa passagem da obra de Mary Shelley ${ }^{3}$, lembramo-nos, de súbito, de Descartes e de como ele também se julgara iluminado e chamado a inaugurar uma nova filosofia e, com ela, ampliar as fronteiras do conhecimento que, indiretamente, contribuiria para o surgir de uma nova Era. Não ficava longe disso o inglês Francis Bacon e sua utopia tecnológica (Nova Atlântida). Ambos, pilares da Modernidade, convencidos de ser artífices de um novo mundo, de um novo tempo, de um novo caminho... Ambos tomados por um desprezo pela tradição, a tradição crítica da razão. Tal desprezo marcará a era que ajudaram a inaugurar... a Era Moderna.

Paripasso ao conto de Mary Shelley, (re)lemos textos de Enrique Dussel e sua filosofia/ética da libertação, nas aulas de Filosofia Prática I, leitura esta que, inicialmente,fizemos nos idos dos anos 80 e que lá a havíamos deixado. Dantes como agora estremecia-nos imaginar que, também no filósofo latino-americano, um certo lampejo luminoso podia-se vislumbrar em sua convicção de ser ele o porta-voz de uma nova filosofia, disposta a revelar o enigma da libertação latino-americana, a indicaro caminho das pedras rumo à realização da utopia libertária dos ameríndios. Se acrescentarmos a isso um certo "quê" salvacionista de um catolicismo arraigado,a semelhança com o filósofo moderno francês fica um pouco mais atormentadora.

De qualquer forma, devemos confessar que o primeiro contato com suas ideias foi sedutor e muito contribuiu na articulação de um engajamento alvissareiro na periferia do mundo. Naturalmente, que ali vivemos uma bela experiência de comprometimento, mas de uma ingenuidade sem par, onde reduzíamos a filosofia a um instrumental de articulação de um discurso de sustentação quase ideológica para um engajamento assentado numa análise muito precária da conjuntura e do fenômeno humano. Nada estranho aos idos dos anos 70/80, especialmente entre teólogos, filósofos, pedagogos, teatrólogos... da libertação.

Retomando a leitura de E. Dussel, na atualidade, enxergamos que nenhum exercício de leitura é completamente perdido, há sempre o que se

3 SHELLEY, M. Frankenstein ou o Prometeu moderno. Trad. de Adriana Lisboa. Rio de Janeiro: Nova Fronteira, 2011. 
aproveitar, pelo menos para tomar consciência das razões que nos levaram, outrora,a abandona-la.

O que segue, nas próximas linhas, é apenas uma leitura, entre tantas outras possíveis, da experiência de retomar alguns dos textos de e sobre Dussel. Faremos uso do esquema com Dussel, para além de Dussel que o próprio autor tanto usou (em relação a outros autores) nos textos que lemos. Ainda não sabemos bem o rumo dessa conversa, mas o que podemos afirmar é que não há, aqui, a pretensão de dizer $a$ verdade sobre Dussel. Este é tão-somente um relato restrito à experiência pessoal de contato com os poucos textos que pautaram os encontros da disciplina acima referida. Nesse intento, servir-nosemos do instrumental teórico-conceitual arendtiano, particularmente no que diz respeito aos conceitos de ação e de pensamento.

\section{Com Dussel... Aspectos marcantes do pensamento dusseliano}

Há vários aspectos ou nuances do pensamento de Dussel que são merecedores do mais sincero reconhecimento. Aqui, destacaremos três deles que, de certa forma, são reveladores da perspectiva assumida por sua filosofia e do compromisso ético (praxis libertadora/transformadora) que seu pensamento inspira.

Quanto à questão se há alguma originalidade em Dussel, é difícil divisar. Parece haver nele um esforço de trazer ou de ser a expressão de uma novidade...um novo pensar latino-americano. Não entraremos nesse debate. A postura de Dussel pode ser vista tanto como louvável por alguns quanto como pretensiosamente questionável por outros. Sem dúvida, Dussel é um pensador polêmico e isso é, no mínimo, interessante.

\subsection{A firmação de uma Identidade latino-americana}

Inegavelmente, a leitura de Dussel reforça, em nós, a consciência de nossa identidade latino-americana. A compreensão de que se tem uma identidade, de que se tem um modo muito singular de ser humano e de estar no mundo, que nos abre para o diálogo com o outro a partir dos horizontes de uma cultura, de uma terra, de uma história... confere, ao exercício do filosofar, um lastro de concretude e um senso de realidade imprescindíveis. 
Há, em Dussel, essa clara compreensão que traduz o filosofar num exercício de comprometimento ético-político com a causa do povo em sua condição de explorado, negado, esquecido, espoliado. Considerando o contexto de uma América Latina marcada pela dominação desde 1492, Dussel capta a urgência de se pensar a filosofia a partir da ética e não da ontologia e, dessa forma, supera a dificuldade desta em fazer uma abordagem antropológica consequente.

Assim, sejam quais forem as discordâncias que possamos ter em relação ao seu pensamento, a exigência dusseliana que sinaliza para uma praxis de libertação ético-política é um postulado que a própria política não pode deixar de colocar: um outro mundo é possível! ${ }^{4}$

Mas, a bem da verdade, esse comprometimento com uma utopia histórica ou com um sonho de libertação do povo latino-americano não é uma das originalidades de Dussel, mesmo reconhecendo que, nele, tal comprometimento teórico-prático é louvável.

\subsection{Uma antropologia latino-americana: o rosto ameríndio do homem}

Enrique Dussel fala de um homem real, de um ser humano que assume um rosto, um rosto ameríndio, inserido na sua mais simples cotidianidade e com o qual nos deparamos quando nos permitimos ultrapassar a acadêmica atitude temática, que substitui a vida pelo discurso sobre a vida, o homem concreto pelo conceito em sua concepção mais abstrata e estreita.

Um Dusselheideggeriano e fenomenológico busca reencontrar o homem em sua atitude existencial, ou seja, num modo propriamente humano de estar no mundo, inserido numa situação existencial, facticamente situado na cotidianidade. Neste ente, o revelar do Ser se traduz enquanto abertura do homem ao mundo, sendo, pela ráxis, que ele se revela e se descobre neste mundo ${ }^{5}$.

Nessa perspectiva compreensiva, com nítidos traços jaspersrianos, o homem, simultaneamente ser finito e (por isso mesmo) ser de transcendência, descobre-se, no mundo, num movimento de totalização nunca acabado, como

4 Cf. CASELAS, J. M. S. A utopia possível de Enrique Dussel: a arquitetônica da Ética da Libertação. Cadernos de Ética e Filosofia Política, v. 15, n. 2, 2009, p. 83. 5 Cf. DUSSEL, E. Para uma ética da libertação latino-americana I. Acesso ao ponto de partida da ética. São Paulo: UNIMEP; Loyola, 1977. p. 88-92. 
um poder-ser, na precária e angustiante situação de um ser que nunca é totalidade realizada, mas tão-somente abertura à totalidade, projetando-se permanentemente na cotidianidade, na qual - atematicamente - articula o viver como um estar-sendo desde o poder-serad-veniente não só meu, mas também nosso... minha família, meu povo, minha nação, meu grupo geográfico-cultural, minha humanidade presente, que são os círculos constitutivos da facticidade ${ }^{6}$.

Apesar de desembocar num ontologismo, de nítido viés cristãosalvacionista ${ }^{-}$“"a destinação do ser’ é dom gratuito que somos como fáctico ser recebido"8 e, portanto, este ser que a nós se destina, por sua vez, destinanos, por suas exigências, à obrigação de realização do ser que somos... -, há, em Dussel, um compromisso de lidar com o homem real, na concretude do ameríndio, marcado, historicamente, pelos traços da exclusão, da expropriação, da negação, da exploração. Pode-se dizer, aqui, que a "descoberta e valorização do conceito de 'rosto do pobre', permitindo o reconhecimento de uma dimensão antropológica prévia à dimensão teológica, na qual se joga a história humana"” é uma novidade admirável em Dussel.

\subsection{O princípio ético da alteridade: o pôr-se frente ao outro como pobre/ excluído}

Entre os princípios da Ética da Libertação, merece especial destaque o princípio da alteridade: acolher o outro como igual e, simultaneamente, diferente é já uma posição ética. Considerando que a ética de Dussel fundamenta-se, também, na criticidade, compreende-se que não é qualquer outro o ponto de partida da Ética da Libertação, mas o outro como excluído, o outro como afetado, de alguma forma, pela dominação, o outro como vítima.

Esse movimento de tomada de consciência do outro como oprimido/excluído ou como o outro negado pela comunidade hegemônica leva à descoberta do outro como sujeito ético na dignidade de ser outro (sujeito autônomo, livre e distinto). Tal descoberta, implica, por desdobramento, na

6Cf. DUSSEL, 1977, p. 62.

7 Uma curiosa questão deixada por Juan Carlos Saccomano, em sua crítica a Dussel (in: ZIMMERMANN, R. América Latina - o não-ser. Uma abordagem filosófica a partir de Enrique Dussel (1962-1976). 2. ed. Petrópolis: Vozes, 1987. p. 209), não deixa de ser intrigante: "Este fundamento que Dussel tanto busca, não acabará sendo um fundamento teológico, sobre o qual a filosofia já não tem mais nada a dizer?"

8 DUSSEL, 1977, p. 87.

9 ZIMMERMANN, 1987, p. 198. 
responsabilidade pela vida do outro como um pressuposto fundamental a toda expressão linguística proposicional ou argumentativa ${ }^{10}$.

Mas, não é qualquer racionalidade que pode ser o aporte para tal perspectiva ética. Só uma razão ético-originária - anterior a todos os malabarismos do exercício da razão - é aquela em que me descubro, desde sempre, responsável pelo outro que compreendo como vítima de um sistema de dominação. Tal razão está na base de um compromisso ético-crítico de transformação da realidade causadora de vítimas, tal razão é o aporte de uma praxis da libertação ${ }^{11}$.Assim, pode-se sintetizar afirmando que "a Ética da Libertação de Dussel (...) é uma ética da transformação, que se efetua por meio de ações críticas cotidianas e tem como ponto de partida a vítima, o outro em algum aspecto negado-oprimido e afetado-excluido"12.

Por fim, Dussel faz o brilhante trabalho de reforçar a compreensão de que a negação do ser do outro é a raiz dos grandes males. Mas, há que se dizer, isso não é uma de suas originalidades: vários são os pensadores europeus que afirmaram, antes dele, o fundamental princípio da alteridade, de maneira radical e consequente, como Martin Buber, entre outros. Dussel silencia e não diz nada sobre essas referências, restringindo-se a citar Levinas. No entanto, há que se reconhecer que Dussel assume "a metafísica da alteridade, a novidade e a exterioridade do outro (...) [como] um novo princípio originante e originário, a partir do qual, pela práxis, (...) se pode chegar a um novo tipo de convivência humana"13.

\section{Para além de Dussel... Dos limites do pensamento dusseliano}

Um dado curioso da história e uma questão intrigante: por que Nicolau Copérnico, cerca de 100 anos antes de Galileu, que morre em 1642, defende o heliocentrismo e, diferentemente deste, não sofre nenhum tipo de perseguição por parte da Igreja Romana? Teria a Igreja cochilado? Claro que não! Se observarmos o tipo de argumentação (metafísico-especulativa) utilizado por

10 Cf. DUSSEL, E. La ética de laliberación: ante el desafio de Appel, Taylor y Vattimo com respuesta critica inédita de K. O. Appel. Ciudad de México: Universidad Autónoma del Estado de México, 1998. p. 55.

11 Cf. DUSSEL, 1998, p. 54-56.

12 OLIVEIRA, I. A.; DIAS, A. S. Ética da libertação de Enrique Dussel: caminho de superação do irracionalismo moderno e da exclusão social. Conjectura, Caxias do Sul, v. 17, n. 3, p. 90-106, set./dez. 2012. p. 101.

13 ZIMMERMANN, 1987, p. 195. 
Copérnico, compreenderemos que ele não representava uma grande ameaça para a Igreja de Roma que, afinal, fazia uso do mesmo tipo de raciocínio. O que pensar de Dussel que, pretendendo contrapor-se ao eurocentrismo ou à filosofia europeia, utiliza-se do mesmo estilo de articulação das ideias e de formatação do pensamento, bem aos moldes europeus?! Que força tem uma crítica à filosofia europeiaque se utiliza da mesma linguagem, racionalidade e estética? Mais reforça do que melindra, mais legitima do que desautoriza... Há, ao que parece, uma incongruência entre conteúdo e forma em Dussel.

Para além da velha crítica ao academicismo de Dussel, interessa-nos observar que o pensador argentino intenta fazer uma filosofia latino-americana numa linguagem de formatação estética europeia. Nenhum problema se se não tem a pretensão de inaugurar ou elaborar uma tal filosofia ameríndia. Mas, se se intenta algo assim, quase se pode dizer que um catolicismo ariano entranhado no teórico Dussel comprometeu o projeto do militante latino-americano. É decepcionante como não há nenhum traço, de fato, ameríndio em sua escrita, em sua articulação das ideias, em sua forma de abordagem, em sua estética redacional... Se há um conteúdo comprometido com as causas ameríndias, a forma deixa muito a desejar. Até onde fomos na leitura, não se encontra um linguajar ou uma racionalidade ou, se quisermos, uma estética que lembre minimamente o horizonte cultural de povos tais comoFulni-ô, Pankararu, Kapinawá, Atikum, Truká, Xucuru, Kambiwá, Tuxá... ou Guarani, Tupinambás, Ianomâmi... ou ainda, para irmos às raízes culturais da Pátria Grande, Incas, Maias ou Astecas.

Seria um exagero essa observação?! Forma e conteúdo nada tem a ver, contrariando o que pensava, por exemplo, um Hegel? Não é possível uma filosofia com traços estéticos realmente ameríndios? Esse é um limite do intento de Dussel ou a desculpa de "que se viu na contingência de fazê-lo [o acima referido academicismo] porque lhe interessava entrar em diálogo com os filósofos europeus que só nos aceitam na medida em que provamos erudição...”14 está valendo!?! Pensamos que não. Essa desculpa não vale nem para ontem (anos 70/80) nem para hoje, especialmente quando nos deparamos com a simplicidade e a profundidade dos escritos, só para citar um, de um Gadamer.

14 ZIMMERMANN, 1987, p. 206. 
Bem, não vamos nos alongar nessa peleja. Nesta parte, faremos três outras breves considerações críticas ao pensamento dusseliano da maneira mais simples possível. Vejamos.

\subsection{Os silêncios de Dussel: ingenuidade ou furtiva estratégia ideológica?}

$\mathrm{Na}$ arquitetônica da Ética da Libertação, observam-se dois momentos considerados imprescindíveis: um é o momento do diagnóstico ou da análise conjuntural histórico-social (aspecto ético-crítico-negativo), outro é o momento do comprometimento com a implementação de um projeto de transformação (aspecto ético-crítico-positivo). Curiosamente, verifica-se que tanto Gramsci quanto Foucault são considerados no segundo momento, mas completamente esquecidos no primeiro.

Em relação a Gramsci, ressalta-se o polêmico e controverso papel do intelectual orgânico na formação da comunidade de vítimas, mas esquece-se completamente da compreensão gramsciana de que não há dominação se não houver, em certa medida, consentimento. O primeiro conceito (de intelectual orgânico) parece fundamental ao segundo momento de sua análise. No entanto, o segundo aspecto, aqui lembrado, do pensamento de Gramsci, fundamental a uma análise lúcida da conjuntura histórico-social é silenciado.

Segundo Caselas ${ }^{15}$, Dussel pressupõe, nos processos de diagnóstico e de articulação de um novo consenso da comunidade de vítimas, a contribuição de um perito ou intelectual orgânico na implementação de uma investigação científica que explique as causas da situação de negatividade e reformule a proposta de um processo de libertação. Chega a ser ingênua uma tal conjectura se não se problematiza os impactos da presença de tal figura, por exemplo, na correlação de poder que se verifica no interior de uma organização popular, além, é claro, de se acentuar, aqui, muito mais uma perspectiva científicoexplicativa do entendimento afeita à ideia de planificação nos moldes de uma racionalidade estratégico-instrumental do que uma perspectiva filosóficocompreensiva de abordagem das interrelações e das experiências ou vivências intersubjetivas. Mas, vamos focar na primeira observação.

15 Cf. CASELAS, 2009, p. 73ss. 
Por que é ingênua e contraditória a proposta de articulação entre o militante e o perito/intelectual em Dussel? Como argumenta Caselas, porque se se recoloca a assimetria que se critica em Habermas e que se pretende superar; porque esquece que a comunidade de vítimas não é imune à questão do poder: a figura do intelectual desequilibra as (micro)relações de poder. Dessa forma, "a utopia de Dussel aproxima-se rapidamente da construção de uma quimera" 116 , posto que acaba por reproduzir aquilo que tanto se criticou no projeto da Modernidade: o ideário iluminista de uma sociedade perfeita pelo esclarecimento das massas ignorantes. Assustador como tal ingenuidade - do vanguardismo - enchia-nos os olhos nos anos $80 \ldots !$

O esquecimento, no momento do diagnóstico, da máxima gramsciana de que não há dominação sem consentimento, por sua vez, não é ingênuo. Gramsci resguarda, o tempo todo, ao povo a condição de sujeito, mesmo que de sujeito de consentimento. O discurso da vítima, por sua vez, tira desta a condição de sujeito. Será mesma unilateral a ação que gera vítimas?!? O que torna possível a implementação de uma dominação europeia, entre outros fatores, senão uma cultura (já presente entre nós, ameríndios) que se caracteriza pela presença de estruturas de dominação já instituídas?

Apenasen passantDussel, nos textos que tivemos acesso, articula uma percepção crítica da cultura popular ${ }^{17}$. Inegavelmente, além de grandes e belos valores, encontramos na história de vários povos indígenas, nítidos traços de uma cultura da violência, da negação da singularidade e da alteridade, da intolerância em relação à diferença... silenciados, ocultados (estratégicaideologicamente?) peloautor. Tal esquecimento compromete a realização de um diagnóstico mais consequente da condição de dominação e nos impede de vislumbrar que os processos de libertação implicam uma articulação mais complexa e profunda.

Em relação ao Foucault, o pensador é lembrado ao se reportar ao conceito de razão estratégica, fundamental no âmbito da exequibilidade prática. No entanto, o conceito de microfísica do poder passa batido. Seria indispensável pensar o poder em rede não só no segundo momento da arquitetônica de sua Ética da Libertação, mas também no primeiro, quando se

16 CASELAS, 2009, p. 74.

17 Cf. DUSSEL, 1998, p. 167. 
assume o conceito de vítima. Assume Dussel uma concepção tradicional de poder, circunscrevendo-o em certas instâncias e/ou espaços delimitados?

Aproveitamos, já fechando este tópico, para ressaltar ou mesmo estranhar a compreensão de "povo" presente em Dussel. Há uma dubiedade: por um lado, quando ele fala do outro como o pobre, o excluído, o explorado, o dominado... a vítima, vislumbramos os que estão completamente à margem do sistema (?) e de quaisquer estruturas organizacionais, compreendemos tratar-se do povão. E isso é belo em seus textos! Porém, por outro lado, causanos espécie o fato de que toda vez que o autor rotula ou identifica este "povo", ele reporta aos "movimentos sociais, populares, feministas, ecologistas..." ${ }^{18}$ ou aos "novos movimentos sociais, partidos políticos críticos..." de ser "o povão", que superlota as periferias latino-americanas. Quanto à sinalização da categoria povo como ator coletivo imprescindível à universalização de uma contra-hegemonia, deixemos para problematizar no próximo tópico.

\subsection{Dussel e a senda estreita do marxismo}

Como observa bem Zimmermann (1987, p. 210), ainda nos anos 80, Dussel, "como marxista que é - e em seu texto se evidencia todo o seu dogmatismo - permanece com seu instrumental teórico-analítico", ancorando, em algumas teses marxistas, a viabilidade da arquitetônica da sua Ética da Libertação. Tal perspectiva teórico-analítica, por sua vez, compromete, em vários aspectos, o arcabouço de sua construção teórica e torna-o refém de categorias conceituais estreitas, o que esclarece, pelo menos em parte, a fragilidade tanto da diagnose quanto da exequibilidade previstos em seu projeto. Além disso, explica os silêncios do autor em relação a questões comoa dos jogos internos de poder dos segmentos dos excluídos, entre outras.

Ater-nos-emos, aqui, apenas a uma pequena mostra de aspectos reveladores da estreiteza da senda marxista, presentes na arquitetação do pensamento dusseliano.

Como verifica Caselas $^{20}$, a viabilidade da arquitetônica da Ética da Libertação ancora-se na antevisão da impossibilidade de perpetuação do 18 DUSSEL, 1998, p. 24.

19 Ibid., p. 29.

20 Cf. CASELAS, 2009, p. 75-6. 
sistema hegemônico por conta de suas contradições ou crises estruturais que acabam por criar as condições para a praxis libertadora. Sabemos hoje, mais do que conseguimos dar conta nos anos 80 , que, sem considerar os efeitos e/ou desdobramentos que tais crises provocam à comunidade de vítimas, toda diagnose será superficial ou inconsistente. Além disso, esta ideia de uma comunidade de vítimas autoconsciente reporta à velha noção marxista de proletariado e às velhas categoriais nela imbricadas que não cabem mais ou são seriamente insuficientes para a articulação de uma crítica consequente ao atual contexto geopolítico-econômico e sua desterritorialização do poder de antigos espaços ou configurações. Acrescenta-se a isso o fato de que Dussel, ao assumir tal perspectiva analítica, supervalorizando a categoria de luta de classes como chave explicativa, em relação à qual tudo o mais é pura perfumaria, secundarizará questões como as de gênero, ambiental e da singularidade da pessoa humana, que muito superficialmente aparecem nos textos lidos.

No entanto, outro é o foco da análise que segue, neste tópico: a tese de uma classe como agente histórico de transformação, ou melhor, a ideia de sujeito coletivo subentendida na argumentação dusseliana. Sobre ela teceremos algumas brevíssimas considerações críticas, já sinalizadas, nos anos 50, por Hannah Arendt, em $A$ condição bumana ${ }^{21}$, especialmente em sua análise sobre o advento do social.

No contexto em que a pensadora analisa a concepção política moderna, num confronto com teses da concepção clássica, ela observa que o advento do social, que desloca o "sombrio interior do lar para a luz da esfera pública" (2014, p. 46), tornou turva a antiga fronteira entre o privado e o político e alterou o significado desses dois termos: o que hoje denominamos de privado restringe-se à esfera da intimidade. Assim, enquanto para os gregos, o privado indicava o estar privado de algo (privação) - daí que, para eles, quem se restringisse a uma vida privada não seria inteiramente humano -, para a concepção moderna, a privatividade não tem tal conotação, mas refere-se ao abrigo do que é íntimo, e este, por sua vez, "foi descoberto não como o oposto da esfera política, mas da esfera social” (2014, p. 47), com a qual, visto da perspectiva grega, está mais relacionado.

21 Cf. ARENDT, H. Os domínios público e privado. In: A condição humana. Trad. Roberto Raposo. 12. ed. rev. Rio de Janeiro: Forense Universitária, 2014. cap. II, p. 27-96. 
Bem, feito tal preâmbulo, queremos chegar a uma rápida caracterização do domínio do social e, quem sabe, por essa via, demonstrar a estreiteza ou mesmo o equívoco de leitura de Marx, aporte teórico da Ética da Libertação de Dussel.

Segundo compreende Arendt, o fenômeno do conformismo é intrínseco ao domínio do social, posto que a ideia de igualdade é assumida como unidade, e esta é absorvida, pelos grupos sociais, na Modernidade, aos moldes de unidade familiar: "a igualdade dos membros desses grupos, longe de ser uma igualdade entre pares, lembra antes de tudo a igualdade dos membros do lar ante o poder despótico do chefe do lar..." (2014, p. 49). Dessa forma, enquanto o domínio público era o lugar de manifestação da individualidade ou reservado aos feitos singulares, o domínio do social configurar-se-á como o contexto do comportamento normatizado, que substituirá a ação.

A suposição de que os homens se comportam ao invés de agirem em relação aos demais está na base da moderna ciência da economia, que nasce concomitantemente à ascensão do domínio do social, e que, observa Arendt, no uso do instrumento técnico da estatística, afirma-se como a ciência social por excelência ${ }^{22}$. Não é necessário verificar, posto que é óbvio, que a estatística não considera a singularidade das ações, mas apenas o que se configura em grandes números. Grandes números esses que justificam o conformismo, o behaviorismo e o automatismo nos assuntos humanos, subordináveis, dessa forma, a um tratamento matemático. Arendt analisa que "a uniformidade estatística não é de modo algum um ideal científico inócuo" (2014, p. 53), tratase, antes, de um ideal político de uma dada sociedade que se articula com uma dada concepção científica.

Bem, com isso, chega, Arendt, a constatação de que a concepção de homem socializado e da fiç̧ão comunista em Marx, corroboram uma conexão entre ele e os seus predecessores liberais. E, se o sistema (econômico) de Marx parece mais consistente ou mais científico que os de seus predecessores, "o motivo (...) reside primordialmente na construção do 'homem socializado', que é um ser ainda menos ativo que o 'homem econômico' da economia liberal" (2014, p. 52, nota 35). Nessa linha da conexão entre Marx e os economistas liberais, observa-se que são estes que introduzem, no contexto da 
Modernidade, a fiç̧ão comunista, isto é, "supor a existência de um único interesse da sociedade como um todo, que como 'uma mão invisível' guia o comportamento dos homens e produz a harmonia de seus interesses conflitantes"23. Marx difere de seus predecessores pelo fato de ter dado visibilidade à ficção comunista (de interesse único: o bem comum) e, assim, concebe a sociedade "como um único sujeito" ${ }^{24}$, ferindo o princípio da pluralidade, imprescindível ao domínio público da política.

Outro equívoco de Marx refere-se ao significado da vitória do domínio do social. Sobre a significação e caracterização de tal domínio, na era moderna, pode-se pontuar, a partir do olhar de $\mathrm{H}$. Arendt, que, longe de significar um eventual surgimento do reino da liberdade, a vitória da esfera do social dará lugar a um processo crescente de administração burocrática que, como uma mão invisivel, governa ou padroniza o comportamento em todas as áreas da vida. Uma outra característica do domínio do social é o seu caráter monolítico: “o seu conformismo, que só admite um único interesse e uma única opinião" 25 , apoiando-se na tese da unicidade da espécie humana, própria da esfera privada ou do homem biológico focado na própria sobrevivência.

Não é à toa que o domínio do social será o âmbito no qual o processo vital estabeleceu-se como público e será, consequentemente, o foco de uma sociedade que considerará tudo o que faz "como modo de sustentar suas próprias vidas e as de suas famílias" ${ }^{26}$, dando a isso importância e visibilidade pública. Marx, um dos maiores representantes da moderna filosofia da vida, cuja última referência é a vida e sua fertilidade ${ }^{27}$, ao enfatizar a vida social e o homem socializado, segue, em linhas gerais, a mesma perspectiva da afirmação moderna da vida da espécie e de justificação da necessidade do trabalho. Mas, não entraremos, aqui, nesse debate.

Enfatizamos apenas queDussel, inspirando-se em Marx, coerentemente, destacará, como princípio material universal de sua Ética da Libertação, "a reprodução e o desenvolvimento da vida do sujeito humano" 28 , corroborando uma sintonia com o moderno paradigma biológico e seu

23 Ibid., p. 53.

24 Ibid., p. 54, nota 36.

25 ARENDT, 2014, p. 56.

26 Ibid., p. 57.

27 Cf. Ibid., p. 388-9, nota 76.

28 DUSSEL, 1998, p. 9; 10;11; 12; 13; 14; 15; 17; 19; 26; 27; 28... repetidas vezes. 
processo vital metabólico. Aliás, há que se reconhecer que, em Marx, articulamse muito bem a introspecção cartesiana e o modelo biológico e seu processo metabólico, o que, no desdobrar-se das reflexões, tanto em Marx quanto em Dussel, traduzir-se-á num certo flerte com os simplórios malabarismos de uma racionalidade estratégico-instrumental, que tudo subordina aos esquemas mecanicistas da categoria meios e fins.

Por fim, com o domínio do social, configura-se, dirá Arendt, uma sociedade do interesse único e cujo sujeito é a classe ou o gênero humano, não mais o homem ou os homens. A esfera pública perde consistência e deixa de ser o lugar da manifestação, por excelência, da pluralidade das singularidades, tornando-se, paulatinamente, o lugar que "requer de seus membros um funcionamento puramente automático, como se a vida individual realmente houvesse sido submersa no processo vital global da espécie...”29. A perda de experiência humana, que tal situação acarreta, além de empobrecer a ação, que passa a ser concebida sob a lógica do produzir ou fabricar, submetida aos esquemas da racionalidade estratégica dos meios e dos fins, respingará também no campo da atividade do pensamento, reduzido a um cálculo de consequências, não passando de uma mera função do cérebro.

\subsection{O flerte com uma razão estratégica: a instrumentalização do agir e do pensar}

O que se coloca em questão, a seguir, não é, obviamente, a instrumentalidade como tal, isto é, o emprego de meios para atingir um fim, mas antes a generalização da utilização da categoria meios-fins, própria da experiência da fabricação ou do universo do homo faber, como critério último para todas as esferas da vida e do mundo dos homens. É o que, segundo indica os seus textos, parece fazer Dussel, tomado pela urgência de realização de sua utopia histórica: o resgate de uma razão instrumental que, ao assumir uma perspectiva crítica, é tomada como ética.

Contudo, há que se indagar: subsumir, criticamente, a razão estratégico-instrumental é suficiente para garantir a ela um "lugar insubstituível na ética" ${ }^{30}$, como defende Dussel? Neste tópico, nem queremos chegar a tanto.

29 ARENDT, 2014, p. 400.

30 DUSSEL, 1998, p. 17. 
Interessa tão-somente verificar as repercussões preocupantes do uso da categoria meios-fins, inerente a tal razão, nos campos da ação e do pensar.

$\mathrm{Na}$ esteira de Marx, Dussel "elege a vida como critério último de valor e princípio material" ${ }^{1}$. Nessa linha, segundo as suas próprias palavras, "vale o que tem relação com a vida, não vale o que não tem relação com a vida. Vale mais o que tem mais relação com a vida" ${ }^{32}$. Dessa forma, o projeto ético de libertação - cujo princípio imperativo é a produção, a reprodução e o desenvolvimento da vida humana - também será fruto da razão estratégicoinstrumental, uma vez que esta "se propõe e define fins políticos e econômicos (a utopia histórico-possível)" "33. Esta razão tem lugar insubstituível em seu projeto ético porque “ocupa-se, exatamente, da 'factibilidade' eficaz da ação humana" ${ }^{34}$; porque, arrematará Dussel, o bem ou a eticidade vivente traduz-se como "o eticamente verdadeiro (que permite viver), moralmente válido (...) e factível (segundo a razão instrumental e estratégica) efetuado" ${ }^{35}$.

Faremos, na sequência, dois breves movimentos, ambos a partir do aporte teórico arendtiano: um buscará identificar as repercussões desvirtuadoras de tal perspectiva instrumentalizadora no âmbito da ação humana e outro intentará o mesmo no que se refere à atividade de pensar.

Ação e pensamento, apesar de guardar entre si significativas diferenças, “tem muito mais em comum entre si que qualquer um deles tem com a obra ou com o trabalho. Por si próprios, não 'produzem' nem geram coisa alguma: são tão fúteis quanto a vida" ${ }^{" 36}$. Não são redutíveis a objetos de uso ou a bens de consumo. Reduzidos a meios para são sobremaneira empobrecidos em sua significação, posto que são feridos em suas características fundamentais e, assim, perdem, por fim, a sua potencialidade revolucionária. A Modernidade e sua típica exaltação do homo faber, o homem que, entregue a uma perspectiva utilitarista, instrumentaliza e cuja "instrumentalização implica a degradação de todas as coisas a meio" ${ }^{37}$, reduz a ação a um fazer meramente utilitário e o

31 OLIVEIRA; DIAS, 2012, p. 97.

32 DUSSEL apud OLIVEIRA; DIAS, 2012, p. 97.

33 Idem, , 1998, p. 58.

34 Ibid., p. 17.

35 Ibid., p. 18.

36 ARENDT, 2014, p. 116-7.

37 Ibid., p. 194. 
pensar a um cálculo de consequências, prisioneiro dos encadeamentos dos meios e fins.

No que diz respeito à ação, há que perscrutar suas características mais relevantes para, assim, compreender as razões da resistência à mesma pelos que se deixam seduzir pelas promessas de realização, de estabilidade e de certezainerentes à perspectiva da instrumentalização. Ao que parece, esquecem esses que, diferentemente do processo de fabricação, que é inteiramente determinado pelas categorias dos meios e do fim, a ação, apesar de ter um começo determinado, jamais tem um fim previsível.

Assim, destacam-se como características relevantes da ação, segundo Arendt: a ilimitabilidade, posto que um ato, por mais pontual que seja, pode gerar um encadeamento de ações e reações que pode mudar todo um conjunto ou extrapolar fronteiras sobre os quais não temos controle; e a imprevisibilidade, uma vez que, diferentemente dos processos de fabricação, o pleno significado da ação só se revela quando ela termina ou mesmo, pensando em termos de processualidade histórica, quando todos os participantes já estão mortos. Daí que, para Arendt (2014, p. 238), “a ação só se revela plenamente para o contador da estória [storyteller], ou seja, para o olhar retrospectivo do historiador...". Segundo a pensadora, enquanto o ator estiver empenhado no ato ou enredado em suas consequências dificilmente consegue vislumbrar as significações de sua ação.

Tudo isso revela, especialmente, a fragilidade dos assuntos humanos e confere um alto grau de risco à ação, "que é fútil, ilimitada e incerta com relação aos resultados" ${ }^{\prime 3}$. As fragilidades da ação decorrem da condição humana da pluralidade, condição sinequa non do domínio público, lugar de expressão das singularidades e de manifestação da capacidade humana de agir, compreendendo, aqui, a ação como o "começo espontâneo de algo novo"39.

A resistência à ação - que se caracteriza pela imprevisibilidade dos resultados, pela irreversibilidade do processo e pelo anonimato dos autores - e a tentativa de substituí-la por algo mais confiável ou previsível é, no entanto, muito anterior à era moderna que, na glorificação do homo faber, apenas levou, tal intento, ao ápice ${ }^{40}$. A fuga da fragilidade da ação para a solidez da 38 ARENDT, 2014, p. 242.

39 Ibid., p. 289.

40 Observa H. Arendt que a tentativa de substituir a ação pela fabricação é visível em todos os argumentos contra a democracia ou contra os elementos essenciais da 
estabilidade e da segurança e a certeza da produtividade tem sido recomendada pela filosofia política desde $\operatorname{Platão}^{41}$ que, por primeiro, articula os delineamentos de um sistema político utópico, cuja referência, atravessando séculos, constitui "uma tradição de pensamento político na qual o conceito de ação era, consciente ou inconscientemente, interpretado em termos de produção e fabricação" ${ }^{\prime 2}$.

Juntamente com Marx ${ }^{43}$, Dussel deita raízes em terras mais profundas da tradição. "A substituição da ação pela fabricação e a concomitante degradação da política em um meio para atingir um fim supostamente 'superior' (...) são tão antigas quanto a tradição da filosofia política" ${ }^{44}$ : na Antiguidade, a proteção dos bons contra o domínio dos maus (PLATÃO, República, 347; AGOSTINHO, Epistolae, 153.6); na Idade Média, a salvação das almas; na era moderna, a produtividade e o progresso da sociedade... chegando a Marx e a Dussel que, nesse particular, não representam nenhuma ruptura nem promovem nenhuma inversão da tradição.

Analisa Hannah Arendt que toda a terminologia da teoria política e do pensamento político incorporou, com sucesso, essa transformação da ação em uma modalidade de fabricação, tornando impossível discutir política sem o emprego da categoria meios e fins e sem que se pense em termos de

política, uma vez que objetiva suprimir a condição humana da pluralidade (Cf. ARENDT, 2014, p. 273).

41 Segundo Arendt (2014), a obra O político, de Platão, é do ponto de vista teórico, "a versão mais 'sintética e fundamental' da fuga da ação" (p. 275). Confira análise nas p. 275-281, na qual a autora faz referência a várias obras de Platão. Merece, também, atenção a distinção, feita por Platão, entre os verbos archein (começar/governar) e prattein (realizar/agir), levando à substituição da ação pela "mera execução de ordens" (p. 276).

42 ARENDT, 2014, p. 282.

43 Não é prioridade aqui, mas não deixa de ser curioso observar, com Arendt (2014), que, considerando que o processo de fabricação sempre comporta o elemento da violência, esta "sempre desempenhou função importante no pensamento e nos esquemas políticos baseados na interpretação da ação em termos de produção" (p. 282). Na era moderna, quando se afirma o homem como sendo basicamente um bomo faber, deu-se lugar a uma certa glorificação da violência como meio a se justificar em vista de certos fins: uma "série de revoluções, típicas da era moderna (...) revelam a mesma combinação do antigo entusiasmo romano pela fundação de um novo corpo político com a glorificação da violência como único meio de 'produzir' esse corpo" (p. 282). Marx, por sua vez, ao afirmar, na obra $O$ capital, que "a violência é a parteira de toda velha sociedade grávida de uma sociedade nova" (apud ARENDT, 2014, p. 2823), sintetiza a convicção, dominante na era moderna, de que a história é "produzida" pelo homem, tal como a natureza é "produzida" por Deus.

44 ARENDT, 2014, p. 284. 
instrumentalidade ${ }^{45}$. Essa tradição, inaugurada por aquele que desenha a primeira utopia política, na Antiguidade, e que chega até ao autor da utopia (ameríndia) transmoderna dá a dimensão da força da tentação de eliminar os riscos e os perigos da ação pela introdução, no âmbito das relações humanas, das categorias, muito mais sólidas e confiáveis, de instrumentalização ${ }^{46}$.

No que se refere à atividade de pensar, não há, nos textos lidos de/sobre Dussel, uma abordagem específica. No entanto, tais textos evidenciam tanto a sua filiação à Marx - e, por decorrência, ao modelo biológico e seu processo metabólico, que assume a vida como critério supremo -, para o qual “o próprio processo de pensar é um processo natural” ${ }^{47}$ e, portanto, como todos os homens e todas as demais atividades humanas, está sujeito a uma força natural, a força do próprio processo vital ${ }^{48}$; quanto o seu foco nas benesses da cognição ou da inteligência nos processos de diagnose da alienação e de articulação de um novo consenso da comunidade de vítimas, a partir da colaboração da ciência e da técnica. Não é à toa que Dussel pressupõe, como acima mencionado, a contribuição de um perito/intelectual orgânico na implementação de uma investigação científica que explique as causas da situação de negatividade e reformule a proposta de um processo de libertação.

Há, sem dúvida, em Dussel, como em todo aquele que se deixa tomar por um afã instrumentalizador, uma expectativa por resultados palpáveis, que só podem ser alcançados mediante processos cognitivos, não pela atividade do pensamento. Enquanto a cognição sempre persegue um fim definido, que pode ser determinado, inclusive, por considerações práticas, a atividade de pensar, pontua Arendt, é "um daqueles atos que (...) têm o seu fim em si mesmos e não deixa nenhum produto, externo e tangível, no mundo que habitamos" ${ }^{49}$. Enquanto é um invisível lidando com invisíveis, esta atividade, dependente da imaginação, não é condicionada por nenhuma das condições do mundo, obedecendo apenas às leis inerentes à própria atividade ${ }^{50}$. O que não quer dizer,

45 Cf. Ibid., p. 283.

46 Cf. Ibid., p. 285.

47Afirmação encontrada em uma carta de Marx a Kugelmann, de julho de 1868. Cf. ARENDT, 2014, p. 399.

48 Cf. ARENDT, 2014, p. 398-9.

49 ARENDT, H. A vida do espírito. Trad. Cesar Augusto Almeida, Antônio Abranches e Helena Martins. Rio de Janeiro: Civilização Brasileira, 2009. p. 149.

50 Cf. Ibid., p. 88-9. 
no entanto, que o pensamento não tenha um papel importante na busca científica do conhecimento, mas, observa Arendt (2009, p. 71), "é o papel de um meio em relação a um fim". Contudo, quando isso se dá, isto é, quando se utiliza do pensar tão-somente como um meio para alcançar certo fim (verdades factuais, no caso das ciências), nega-se o pensar no seu sentido mais pleno ou stricto sensu' ${ }^{51}$.

Enquanto atividade espiritual ${ }^{52}$, além de ser autônoma, caracterizar-se por uma invisibilidade e, devido à sua natureza reflexiva, portar a capacidade de se realizar como um experimento do eu consigo mesmo, a atividade de pensar traz, como um dos seus principais traços característicos, a sua tendência autodestrutiva em relação a seus próprios resultados ${ }^{53}$. O pensar, que também se configura como um permanente repensar-se, não produz sabedorias perenes, nem insights perfeitos, nem conhecimentos irretocáveis, nem teorias acabadas e não chega a um sentido definitivo. A cada nova situação, é preciso pensar de novo e sempre.O pensamento não produz efeitos duradouros para além dele mesmo. Não há, propriamente, pensamento para além do perdurar da atividade de pensar. Isso, obviamente, torna compreensível "as objeções do raciocínio do senso comum em relação às inutilidades e à irrealidade de todo o empreendimento filosófico" $" 54$.

Para finalizar, duas breves ponderações: uma primeira recorda que tanto o raciocínio do senso comum quanto a cognição científica, além da capacidade de raciocínio lógico ${ }^{55}$, estão comprometidos com a chegada a resultados palpáveis, posto que pertencem ao mundo do visível, do tangível e do verificável. Tais faculdades humanas ou "processos mentais que se alimentam da força cerebral são geralmente chamados de inteligência" ${ }^{56}$.

51 Arendt, em sua análise, reporta-se, como pressuposto, à clássica distinção kantiana (Crítica da Raz̃ão Pura) entre Vernunf (razão) e Verstand (intelecto), entre a faculdade de pensar, pela qual a razão busca um significado, e a faculdade de conhecer, cujo critério mais elevado é a verdade, pela qual o intelecto realiza a cognição.

52A atividade de pensar é uma das três atividades espirituais básicas, a saber, pensar querer - julgar, investigadas por $\mathrm{H}$. Arendt em sua inacabada e derradeira obra intitulada $A$ vida do espirito(2009).

53Cf. ARENDT, 2009, p. 107.

54 ARENDT, 2009, p. 107.

55 Segundo Arendt (2014, p. 213), deve-se ainda "distinguir tanto o pensamento como a cognição da capacidade de raciocínio lógico, que se manifesta em operações tais como deduções de enunciados axiomáticos ou autoevidentes por si mesmos, na subsunção de ocorrências particulares a regras gerais, ou nas técnicas para prolongar cadeias sistemáticas de conclusões".

56 ARENDT, 2014, p. 213. 
Segundo Arendt, a era moderna, equivocadamente, ao compreender, de um jeito muito próprio, que o homem é um animal rationale - como se fosse uma espécie animal que difere de outras por ser dotada de uma força cerebral superior - acabou por confundir a inteligência com a razão ${ }^{57}$. E, vaticina a pensadora, "é óbvio que essa força cerebral e os processos lógicos coativos que dela resultam não são capazes de construir um mundo..." 58 .

Uma segunda e última ponderação diz respeito ao reconhecimento, em Arendt, de que pensar e agir são atividades completamente diferentes ${ }^{59}$; mas, também reconhece a autora, "há mais do que uma mera distinção entre pensar e agir. Existe uma tensão inerente entre esses dois tipos de atividade" ${ }^{60} . \mathrm{Na}$ tradição filosófica, pode-se encontrar tanto o desprezo (como em Platão) por "aqueles que estão sempre ativos e nunca param (...) [para pensar, quanto o flerte com] a ideia de que pensar é igualmente uma forma de agir" ${ }^{\prime 61}$. Pondera Arendt que, apesar do pensamento ser realmente uma atividade, é preciso esclarecer que "atividade [de pensar] e ação não são a mesma coisa, e o resultado da atividade de pensar é uma espécie de subproduto com respeito à própria atividade. Não é idêntico à meta que um ato busca alcançar e visa conscientemente atingir" ${ }^{\prime 2}$.

Cabe lembrar que, não obstante as diferenças entre o pensar e a ação (política), nada mais distante de Hannah Arendt do que a defesa de um pensamento que se isola e desresponsabiliza-se do mundo. Antes há, em seu pensamento e em seu testemunho de vida, uma compreensão singular de que o

57Vide nota 49.

58 ARENDT, 2014, p. 214.

59 Segundo Arendt, há nítidas diferenças entre o pensamento e a ação (política): a atividade de pensar cobra, daquele que a ela se dedica, um retirar-se do mundo prático e das particularidades circunstanciais e, a política, por sua vez, lida com interesses práticos e trata de instâncias diretamente ligadas à esfera pública comum; para pensar é preciso um recolher-se da presença dos outros para pôr-se em presença de si, num diálogo interno e silencioso consigo mesmo e, a ação política, ao contrário, acontece em público, em interação direta com os demais, na compartilha das diferentes doxai; os que se propõe a pensar caminham na direção de ruptura com o senso comum e este, no âmbito da política, diferentemente, será de suma importância uma vez que é a ponte que interliga o povo aos assuntos práticos do mundo compartilhado por todos; o pensar é mais uma tentativa de compreender o que, no acontecer, está oculto ou invisível aos olhos, qual seja, as suas significações e, no contraponto da visibilidade, a ação política é mais uma tentativa de impor ou dominar o que acontece. Cf. também ARENDT, 2009, p. 221-233.

60 ARENDT, H. Responsabilidade e julgamento. Trad. RosauraEichenberg. São Paulo: Companhia das Letras, 2010. p. 170.

61 Ibid., p. 171.

62 Ibid., p. 171. 
pensar, embora se processe na introspecção do diálogo silencioso em que o indivíduo se põe frente a si mesmo, não deixa de com o mundo relacionar-se e de assumir responsabilidade frente ao que nele ocorre.

Em relação a Dussel, pode-se concluir que este, mesmo que articule uma leitura bastante crítica da Modernidade, revela-se, mais do que se poderia, a princípio, cogitar, comprometido com as (in)compreensões por ela assumidas, tanto no que diz respeito à ação quanto ao que se refere à atividade de pensar. Em seu sincero e fervoroso engajamento na busca por um norte para o processo de libertação latino-americano, acaba por ficar refém das mutilações promovidas pelos esquematismos de uma razão instrumental em seu paranoico desejo de converter o desconhecido em algo previsível e controlável, comprometendo a potencialidade revolucionária da ação que, "com todas as suas incertezas, é como um lembrete sempre presente de que os homens, embora tenham de morrer, não nasceram para morrer, mas para iniciar algo novo" ${ }^{63}$. Quanto ao pensamento, que, em seu exercício crítico e autocrítico, guarda em si uma forte tendência autodestrutiva e revela, portanto, ser deuma natureza (quase) anárquica, há que se concluir que ele é - para todos, mas, particularmente, para aqueles que se deixaram seduzir pelas promessas de uma razão instrumental (dita crítica, logo ética) e tomar pela convicção de que já divisaram "o critério universal de "verdade" ${ }^{64}$ desconcertantemente perturbador.

\section{Breve conclusão}

Há uma curiosa observação crítica de Roque Zimmermann (1987, p. 210), ele que confessa não estar certo "de que Dussel fez verdadeira filosofia”, em relação à extensão da obra já publicada pelo pensador argentino. Indaga ele: "não é demais para tão pouco tempo? Não haverá certa pressa, quem sabe motivada até pela urgência histórica da libertação latino-americana, mas sempre demasiada, em ver tudo publicado?" E segue o autor de América 63 ARENDT, H. Trabalho, obra, ação. Trad. Adriano Correia. Cadernos de Ética e Filosofia Política, v. 7, n. 2, p. 175-201, 2005. p. 194.

64 DUSSEL, 1998, p. 10. Tal critério, segundo o autor, sinaliza ou divisa o que é "mediação para a vida do sujeito humano" e que deste enunciado "se deduz o princípio universal material" (p. 10-11). Antes (p. 9), afirmara que "a reprodução e o desenvolvimento da vida do sujeito humano é o critério de verdade (teórica e prática), condição absoluta de possibilidade da existência não apenas dos sujeitos da argumentação como tais, mas ainda dos processos mesmos conceituais e linguísticos". 
Latina - o não-ser questionando a falta de precisão no uso de conceitos ou categorias, que revelam uma certa confusão de terminologia que, por sua vez, acaba por dificultar a identificação dos próprios fundamentos de Dussel.

Arendt, bem antes do surgimento dos escritos de Dussel e da leitura de Zimmermann, num paralelo entre pensamento e obra, afirmara que "o pensamento e a obra são duas atividades diferentes que nunca coincidem completamente: o pensador que desejar dar a conhecer ao mundo o 'conteúdo' de seus pensamentos deve, antes de tudo, parar de pensar e lembrar-se de seus pensamentos" ${ }^{65}$. Dar materialidade ao intangível, trata-se do processo da obra onde não há mais pensamento. Reportara a autora à metáfora do vento utilizada por Sócrates, segundo narra Xenofonte, e também por Sófocles, na Antígona, que relaciona o “"pensamento rápido como o vento" dentre as coisas dúbias, 'assombrosas' (...) com que os homens são abençoados ou amaldiçoados" $"$.

Sócrates, como ninguém, outra coisa não fez senão colocar-se no meio dessa ventania e talvez seja essa a razão de nada ter escrito. Quem deixa o pensamento e começa a escrever, lembra Heidegger ${ }^{67}$, tem de parecer, inevitavelmente, com os homens que se escondem num abrigo, do turbilhão da ventania. O pensamento tornou-se literatura! Ciente está Sócrates, ao que parece, de que este "vento, sempre que surge, tem a peculiaridade de varrer para longe todas as suas manifestações anteriores" ${ }^{6}$. Portanto, é próprio "da natureza deste elemento invisível desfazer e, por assim dizer, degelar o que a linguagem (...) congelou como pensamentos-palavras (conceitos, frases, definições, doutrinas)" "99, que mantemos intocados quando não nos permitimos à ousadia de pensar permanentemente e tão-somente nos contentamos com o exercício da cognição ou com o encadeamento lógico de proposições que levam, seguramente, a uma conclusão. Corrobora-se, aqui, o papel ou o efeito corrosivo do pensamento: todos os critérios, valores, costumes, regras de conduta, padrões do bem e do mal socialmente estabelecidos podem ser colocados em questão.

65 ARENDT, 2014, p. 111.

66 Idem, 2009, p. 196.

67 Cf. HEIDEGGER, M. Qué significa pensar? Trad. RaúlGabás. Madrid: Editorial Trotta, 2005. p. 79-80.

68 ARENDT, 2009, 196-7.

69 Ibid., p. 197. 
Embora o pensar seja um empreendimento perigoso e sem resultados, ponderará Arendt que o niilismo não é o seu produto, como se poderia conjecturar, uma vez que o pensamento coloca em crise as opiniões e os valores aos quais costumamo-nos estar apegados. $\mathrm{O}$ nilismo surge, não da atividade do pensamento, mas "do desejo de encontrar resultados que dispensariam o pensar" perigoso para todos os credos e, por si mesmo, não dá origem a nenhum novo credo"'

Victor Frankenstein, que se julgara iluminado e, assim, tivera o privilégio de descobrir o segredo da reversão da morte à vida, vai concluir, na vida errante que assumirá, ser isso uma maldição. Esse é o dilema que terão que encarar os que se autoproclamam inauguradores do novo ou descobridores do caminho da libertação de um povo e que, no afã de marcar época ou de estabelecer um divisor de águas, entregam-se a uma produção de profusão desenfreada: a imortalidade só tem sentido (ético) se for dom presente naquele que a renegue como a uma maldição... um Wolverine. Nos que desejam eternizar-se, ela carece de todo sentido, a não ser o de configurar-se como uma perdição.

Será este o caso da obra de Enrique Dussel? Ou seja, terá o seu sistema se reduzido a uma doutrina estéril que, ao assumir chave de leitura tão estreita, não mais dá conta da complexidade do real? Mas, há também que se indagar, já deu algum dia?! É polêmico dizer e careceria de uma investigação mais completa e profunda de sua obra. Louvável nele é o sincero comprometimento com a causa de libertação do povo latino-americano, que inspira a muitos, e isso não é pouca coisa.

\section{Referências}

ARENDT, Hannah. Trabalho, obra, ação. Trad. Adriano Correia. Cadernos de Ética e Filosofia Política, v. 7, n. 2, p. 175-201, 2005.

A vida do espírito. Trad. Cesar Augusto Almeida, Antônio Abranches e Helena Martins. Rio de Janeiro: Civilização Brasileira, 2009.

Responsabilidade e julgamento. Trad. RosauraEichenberg. São Paulo: Companhia das Letras, 2010.

70 Ibid., p. 198.

71 Ibid., p. 199. 
A condição humana. Trad. Roberto Raposo. 12. ed. rev. Rio de Janeiro: Forense Universitária, 2014.

CASELAS, J. M. S. A utopia possível de Enrique Dussel: a arquitetônica da Ética da Libertação. Cadernos de Ética e Filosofia Política, v. 15, n. 2, 2009.

DUSSEL, Enrique. Para uma ética da libertação latino-americana I. Acesso ao ponto de partida da ética. São Paulo: UNIMEP; Loyola, 1977.

La ética de laliberación: ante el desafio de Appel, Taylor y Vattimo com respuesta critica inédita de K. O. Appel. Ciudad de México: Universidad Autónoma del Estado de México, 1998.

HEIDEGGER, M. Qué significa pensar? Trad. RaúlGabás. Madrid: Editorial Trotta, 2005.

OLIVEIRA, I. A.; DIAS, A. S. Ética da libertação de Enrique Dussel: caminho de superação do irracionalismo moderno e da exclusão social. Conjectura, Caxias do Sul, v. 17, n. 3, p. 90-106, set./dez. 2012.

SHELlEY, M. Frankenstein ou o Prometeu moderno. Trad. de Adriana Lisboa. Rio de Janeiro: Nova Fronteira, 2011.

ZIMMERMANN, R. América Latina - o não-ser. Uma abordagem filosófica a partir de Enrique Dussel (1962-1976). 2. ed. Petrópolis: Vozes, 1987. 